\title{
Nos tempos de
}

\section{Villa Kyrial}

\section{6

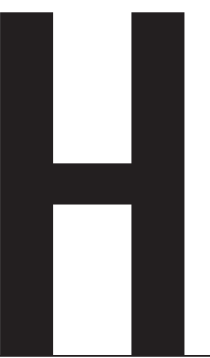 \\ ei de ter sempre a mentalidade de 1906: rua estreita, bonde de burro, casa de pasto, piada do Emílio de Menezes", escreveu Agrippino Grieco, numa da- quelas minúsculas tiras de pa-}

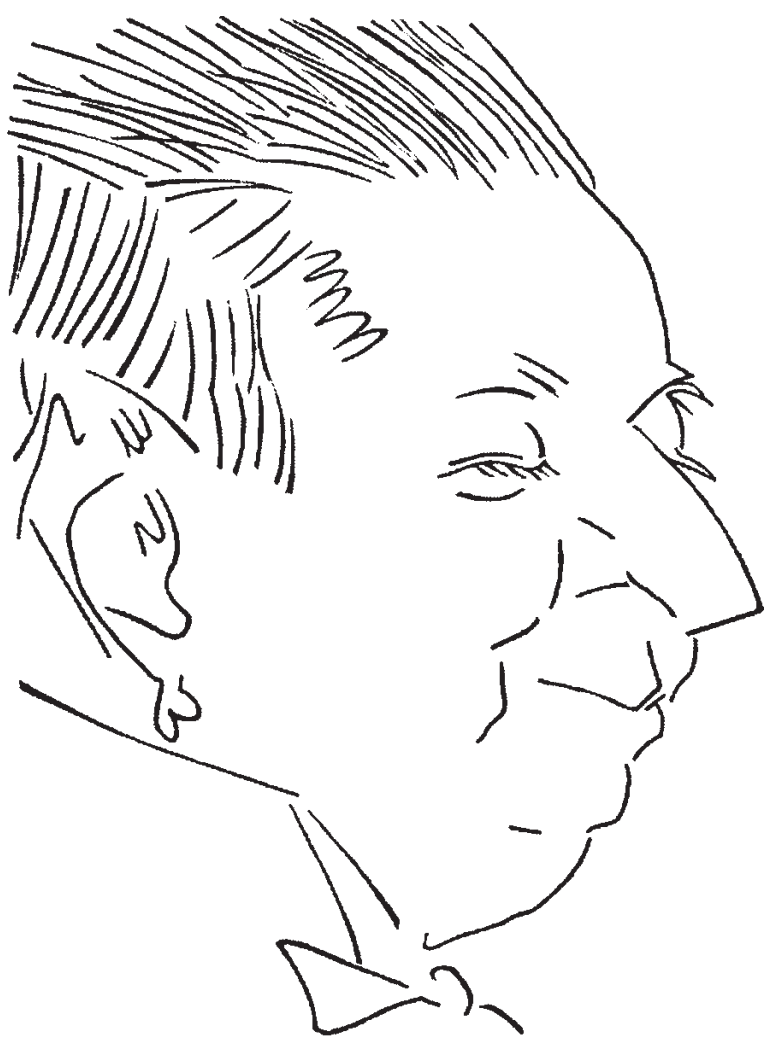

pel, que ele guardava em caixas de sapato - e depois recolhidas no livro Gralhas \& Pavoes, publicado em 1988 (1). Vinda de um crítico irônico e sensível, que completara apenas 18 anos em 1906, a frase resume, pelo lado pitoresco e anedótico, grande parte do que foi a belle époque brasileira. A própria indicação do ano de 1906, na ironia de Grieco, parece mesmo historicamente correta, pelo menos para quem vivia no Rio de Janeiro, pois as ruas estreitas começaram a desaparecer com a abertura da Avenida Central, apareciam os primeiros bondes elétricos e os restaurants já substituíam as incômodas e antigas "casas de
ELIAS THOMÉ SALIBA é professor associado do Departamento de História da FFLCH-USP e autor de As Utopias Românticas (Brasiliense).

Villa Kyrial: Crônica da Belle Époque Paulistana, de Marcia Camargos, São Paulo, Senac, 2001.

Ao lado, caricatura de José de Freitas Valle feita pelo tenor italiano Enrico Caruso em 1917 neiro, Record, 1988, p. 52. 
pasto". Só as piadas de Emílio de Menezes, com seus incríveis trocadilhos, ainda continuariam a circular por mais alguns anos. Coincidindo com o término da administração do prefeito Pereira Passos, 1906 também foi o ano no qual se concluíra a reforma urbana da cidade - capital e centro de irradiação cultural do país - definida por um conhecido refrão da época: “O Rio civiliza-se...". A historiografia mais recente já mostrou o quanto esta "civilização" tomou uma forma compulsória com o "botaabaixo", a remodelação urbana e sanitária da cidade, que expulsou as classes populares para os morros insalubres, exacerbando um clima de violência e de exclusão social que culminaria na Revolta da Vacina.

A reforma urbana do Rio de Janeiro, a vitrine do país, constituiu uma metáfora para engendrar um processo de esquecimento social. Era preciso rapidamente esquecer a cidade colonial, pantanosa, insalubre, que lembrava os tempos da escravidão e do antigo regime - e pensar no futuro do país moderno, construído à semelhança dos modernos estados europeus. $\mathrm{O}$ antigo regime era a monarquia, o novo regime era a república - não aquela das quarteladas e jacobinismos militares da época de
Floriano, mas uma nova, estável e cheia de otimismo no futuro.

Nesta estratégia de batismo de uma "bela época" brasileira, que alternava celebração e esquecimento, o antigo e o moderno, o império e a república eram representados como camadas pouco sedimentadas, numa sobreposição de ritmos temporais diversos. Disseminava-se no país, sem prejuízo das exceções, uma cultura de repúdio difuso à vida rotineira e aos arcaísmos, que seriam a própria negação do progresso, como forma dos indivíduos desamarrarem-se dos modos provincianos e das sociabilidades geradas pela sociedade escravista. O moderno, nesta invenção cultural, significava a incorporação de todos a uma temporalidade comum na direção do progresso. Assim, uma atmosfera que ansiava por cosmopolitismo, gestada a partir do Rio de Janeiro, autêntica capital cultural do Brasil na belle époque, percorreu o país, numa ânsia sôfrega pela europeização e pela modernização. Se a sua difusão foi, com efeito, pouco abrangente e limitada às incipientes manchas urbanas no Brasil de fin-de-siècle, seu efeito desconcertante foi, por isto mesmo, maior e mais profundo. Se durante a independência do país, quase um

\section{Almoço no terraço da Villa Kyrial em}

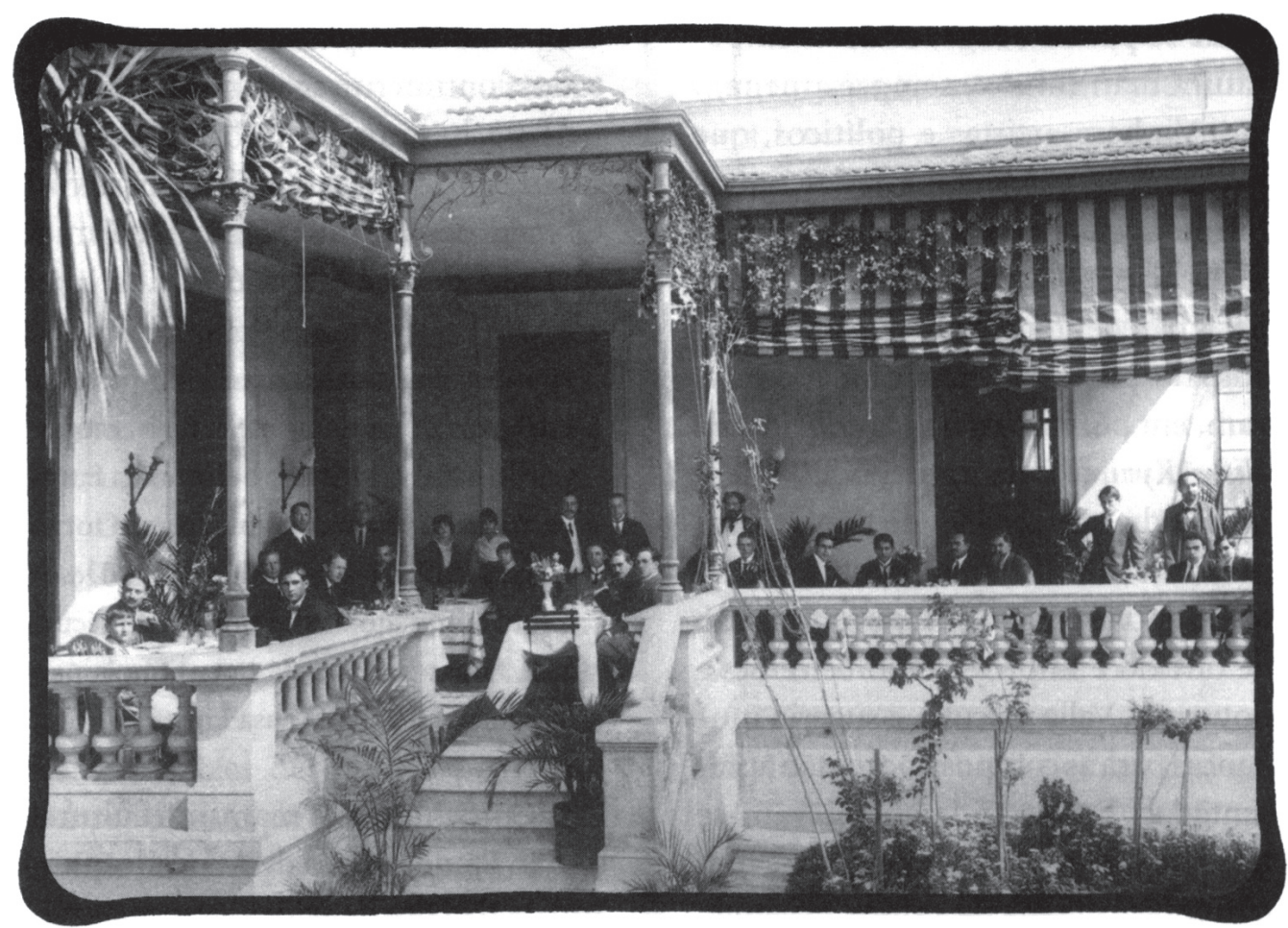




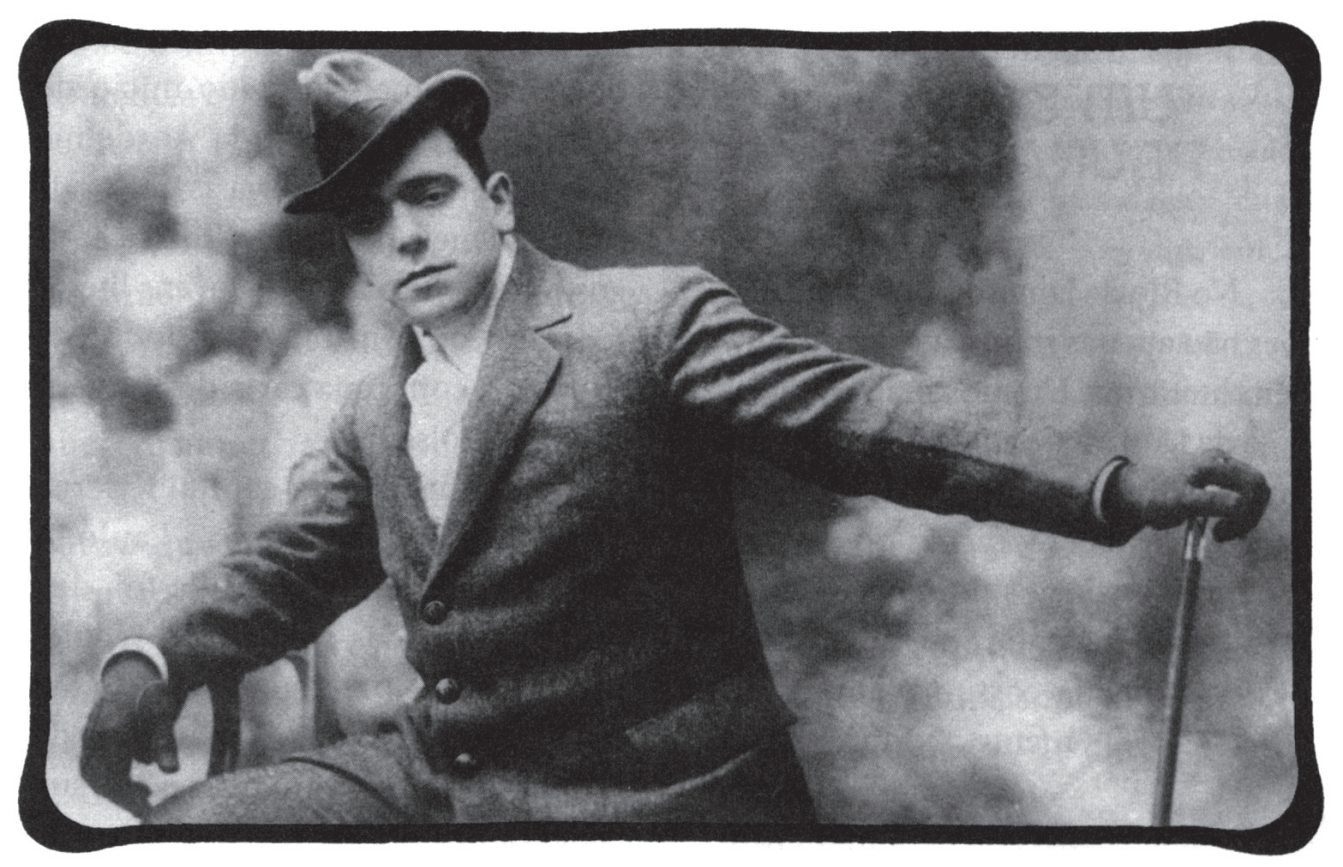

O jornalista e escritor João do Rio

século antes, esta mesma ansiedade expressava-se, culturalmente, pela atração e busca de raízes nativistas e pelo "desejo de ser brasileiros" - na expressão de Antonio Candido - nesse momento, manifesta-se, paradoxalmente, quase que um "desejo de ser estrangeiros" (2).

Mas nenhuma sociedade passa impunemente por um processo de esquecimento forjado e, talvez por isso, ao falarmos de uma belle époque brasileira experimentamos um sentimento sempre hesitante entre a lembrança e o ofuscamento da memória. Na belle époque brasileira, que começa a definir-se na virada do século, vivenciouse, talvez de forma mais ambígua, a tensão expressa na ironia européia do vocábulo, com seu tom meio sério e meio irônico: um amálgama de temporalidades, a sobreposição do futuro no passado e uma visão nervosa e ambígua do país, singularmente hesitante entre a frivolidade e a autenticidade, tudo isso representado pelas inúmeras e incertas correntes literárias e artísticas, predominantes no período. Período inclusive que, nos quadros de uma história cultural do país, sempre foi definido em função do que veio antes ou depois dele"pré" ou "pós" alguma coisa - e nunca em função de suas marcas próprias.

A leitura de Villa Kyrial: Crônica da
Belle Époque Paulistana, de Marcia Camargos, é um poderoso antídoto contra esse imperceptível processo de esquecimento coletivo. Muito menos do que o Rio de Janeiro, São Paulo foi também um microcosmo do país no período da belle époque pois vivenciou, talvez de forma mais ambígua, a tensão expressa na ironia européia do vocábulo "bela época", com seu tom meio sério e meio irônico, hesitante entre a frivolidade e a autenticidade, amalgamando temporalidades, sobrepondo o futuro ao passado numa visão nervosa dos dilemas do país. Mas o esquecimento coletivo foi certamente ainda mais acentuado no caso de São Paulo, que teve sua história cultural profundamente marcada, a partir dos anos 20 , pelo modernismo que - como todos sabemos mas temos dificuldades de explicitá-lo - engendrou uma tabula rasa da tradição, homogeneizando os significados e reiterando aquela tradição da vida intelectual brasileira de começar do zero.

O tema central do livroé a reconstituição da trajetória de José de Freitas Valle, um personagem singulare versátil que foi professor de francês, senador da república, poeta, mecenas, advogado, perfumista e gourmet - enfim, uma personalidade catalisadora de todas as ambigüidades e excentricidades da belle époque brasileira.
2 Cf. N. Sevcendo, Liferatura como Missão; Tensões Sociais e Criação Cultural na Primeira República, São Paulo, Brasiliense, 1983, cap. 1. 


Abaixo,
Porteuse de
Parfums,
de Victor
Brecheret,
1925

Utilizando-se do rico acervo deixado pelo próprio Freitas Valle, Marcia Camargos saiu-se muito bem no difícil desafio de decifrar arquivos pessoais, construindo um painel vivo dessa fase tão esquecida da história cultural paulistana. Isso porque, ultrapassando os limites do seu microcosmo pessoal, Freitas Valle fez de sua residência, a Villa Kyrial, um autêntico núcleo irradiador da cultura paulistana nas duas primeiras décadas do século XX.

E não foi pequeno o impacto da Villa Kyrial sobre a vida cultural da cidade de São Paulo. Apesar dos melhoramentos urbanos introduzidos pela longa administração paulistana daquele outro ilustrado da belle époque, o Conselheiro Antonio Prado, São Paulo ainda mantinha muitos dos traços do seu passado provinciano. Na célebre caracterização de Richard Morse, São Paulo testemunhava a "transição de uma sociedade regional com certas consonâncias universais, para uma sociedade cosmopolita de consonância inteiramente provinciana" (3). Atra-

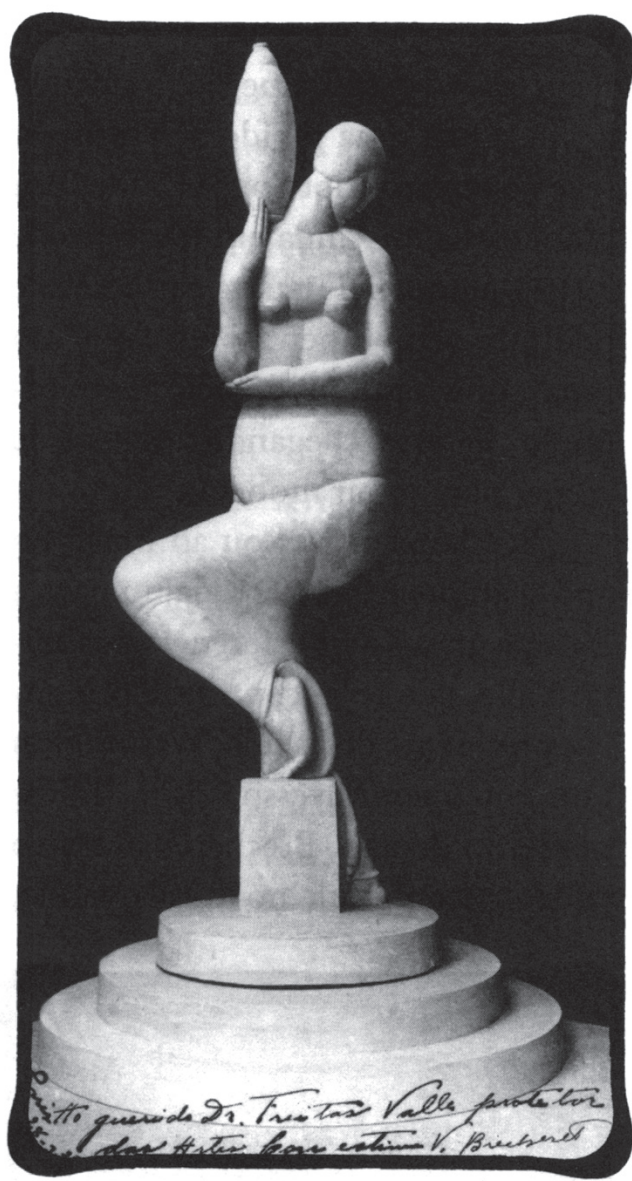
vés de conferências, reuniões, certames, festas, concursos, exposições, serões, Freitas Valle criou um autêntico círculo de sociabilidade cultural em São Paulo. Apoiado em farta e inédita documentação iconográfica e impressa, o livro narra com vivacidade muitos dos eventos realizados na Villa, desde os mais formais, como conferências de escritores famosos; os mais solenes, como os banquetes com cardápios requintados; até os mais prosaicos, como os campeonatos de pinguepongue. Nesses ca- sos, a personalidade de Freitas Valle se desdobrava em Maitre Jean Jean, organizando os cardápios; Fre Val, mestre perfumista ou Jacques D'Avray, escrevendo poemas simbolistas. Apesar de a extravagância se afigurar acintosa numa sociedade intrinsecamente excludente e desigual, a multiplicação de personagens, muito bem analisada pela autora, pode ser compreendida no ambiente cultural ambíguo da belle époque. Ambíguo porque penetrado pelos mais diversos ismos e modismos: uma cultura ainda incapaz de se desligar totalmente da tradição, produzindo uma literatura picante, cheia de rebeldia existencial, porém, na sua maior parte, frívola, afetada e superficial - enfim, uma cultura na qual se experimentava aquele fenômeno tãofin-desiècle, de uma consciência dividida entre uma visão mecanicista e uma visão intuitiva da vida. Na análise clássica da atitude decadentista, como uma reação oblíqua e estética à modernidade tecnológica, o caráter transcendente da beleza artificialmente criada concentrava-se na originalidade do indivíduo excêntrico, o dandi, pois com seu vestuário e suas performances ele conseguia concretizar uma revolta racional contra a vulgaridade da época. Diante de um mundo artificial e mecânico ele buscava uma conotação positiva, que encontraria expressão em diferentes formas de escapismo (4). Em algumas de suas atitudes Freitas Valle lembrava aqueles singularíssimos personagens dos romances de João do Rio, como o Barão de Belfort quando não lembrava o próprio João do Rio, de quem, aliás, foi amigo. Em certos momentos pitorescos, tão bem narrados por Marcia Camargos, Freitas Valle parecia mesmo uma mistura de João do Rio com Olavo Bilac, mantendo um pé na extravagância outro na convenção. Muito embora a emulação desse comportamento fosse uma estratégia para criar, num cenário rarefeito, uma ponte de comunicação e expressão peculiares à sua personalidade, Freitas Valle foi além desse quadro, transformando seu mecenato num instrumento de autêntico investimento social. A criação e estímulo ao Pensionato Artístico possibi- 
litou a continuidade da formação artística de inúmeros artistas, como Anita Malfatti e Victor Brecheret-para citar apenas dois, entre os nomes mais notáveis.

E isto não era pouco numa sociedade que carecia de uma esfera pública de expressão e de difusão cultural. Naturalmente, a Villa Kyrial foi uma espécie singular de salão privado improvisado em espaço público, embora ainda estivesse longe dos ideais iluministas de uma esfera pública, já que, embora toleráveis certas transgressões, os limites eram dados pela autoridade do dono da casa. A autora enumera, sobretudo no capítulo "República das Letras", todas as críticas, ironias e sátiras - algumas impiedosas, como as de Monteiro Lobato - à figura de Freitas Valle, o "senhor da Villa Kyrial" e, sobretudo, achincalhando seus versos, sempre escritos em francês.

Vários jornalistas ou escritores de ocasião, naturalmente à margem do circuito de sociabilidade criado e animado a partir da famosa Villa Kyrial, multiplicaram suas sátiras e paródias à figura do ilustre mecenas. A referência a Juó Bananére (pseudônimo de Alexandre Marcondes Machado), que, segundo a autora, “acabou demitido, muito provavelmente devido a pressões de estudantes de Direito, após ter parodiado discurso nacionalista de Olavo Bilac", merece um reparo, já que o episódio se revelaria importante no campo cultural paulista, logo após o início da campanha nacionalista de Bilac, em 1915. Os testemunhos daépoca são claros: Juó Bananére foi demitido pelas pressões dos estudantes da Faculdade de Direito que apenas ajudaram a fermentar as desavenças pessoais do bardo macarrônico com Oswald de Andrade, em $O$ Pirralho. Desavenças que continuaram no ano seguinte, 1916, após as críticas ferinas de Bananére às peças teatrais Mon Coeur Balance e Leur Âme, de Oswald e Guilherme de Almeida-lidas no Teatro Municipal pelas atrizes francesas da Cia. Dramática de Lugné-Poe. Os dois episódios foram muito reveladores dos compromissos que a jovem intelligentsia de São Paulo tinha com aquele nacionalis- mo algo difuso mas que se nutria de única certeza: sua raiz paulista, ávida por construir e reforçar uma hegemonia e, se possível, estendê-la ao campo cultural (5).

O livro nos traz ainda revelações sugestivas e bem documentadas a respeito das relações da notável figura de Freitas Valle com a extensão da hegemonia política paulista para o campo cultural, cujo momento decisivo será em 1922. Queiramos ou não, o estilo de mecenato ilustrado de Freitas Valle estará presente no circuito cultural paulistano e, no limite, indicou certas linhas de relacionamento futuro entre as elites ilustradas paulistas e os artistas e intelectuais. As bases destes relacionamentos futuros, naturalmente, serão outras.

No capítulo final, o livro narra o ostracismo voluntário de Freitas Valle no final dos anos 20 mas, sobretudo, depois do episódio político de 1930, que encerrou uma fase da história republicana brasileira. O "senhor de Villa Kyrial" retira-se da cena cultural paulistana por circunstâncias da sua biografia e da própria história brasileira. Mas também - é importante mencionar porque o seu comportamento de generosidade e bonomia, bem ao estilo belle époque, assim como o seu cosmopolitismo - ainda que aparente - haviam se tornado um tanto inconvenientes, num cenário no qual predominava uma entranhada atitude nacionalista. Em termos de atitudes intelectuais, o confronto não era mais entre nacionalismo e cosmopolitismo mas entre um nacionalismo intransigente contra outro mais conciliador e assimilacionista.

Refazendo a trajetória singular da Villa Kyrial e do seu animador, o livro de Marcia Camargos representa uma contribuição inestimável para quebrar com o esquecimento social a que ficou relegada essa época tão fértil da história paulista. Fazendo coro com trabalhos recentes que examinam a ebulição cultural paulistana na belle époque, do ponto de vista da produção musical, da arquitetura, da imprensa e das artes (6), a historiografia assume, com este livro notável, a sua mais autêntica vocação de desmistificadora da memória social.

\footnotetext{
Cf. Elias T. Saliba, "Juó Bananére, o Raté do Modernismo Paulista?", in Revista de História, 137, São Paulo Depto. de História da USP 1997, pp. 113-22, e "luó Bananére e a Literatura Macarrônica na la República" in Edgar de Decca e Ria Lemaire (orgs.), Pelas Margens; Outros Caminhos da História e da Literatura, Campinas, Editora da Unicamp, 2000, pp. 27-54.

6 Para só ficar nos trabalhos mais recentes, podemos lembrar, no campo da produção e difusão musical: J. Geraldo Vinci de Moraes, Sonoridade Paulistanas: a Música em São Paulo no Início do Século XX Rio de Janeiro, Funarte/Bienal 1999; no campo de arquitetu ra: Paulo Garcez Marins, Atro vés da Rótula: Sociedade Arquitetura Urbana no Brasil São Paulo, Humanitas, 200 no campo da imprensa e das revistas semanais: Ana Luiza Martins, Revistas em Revista; Imprensa e Práticas Culturais em Tempos de República 1890-1922, Tese de doutora do em História Social-USP 1998: e, no campo das artes: Miriam Silva Rossi, Organiza ção da Campo Artístico Paulistano, dissertação de mestrado, FFLCH-História Social, USP, 2001.
} 